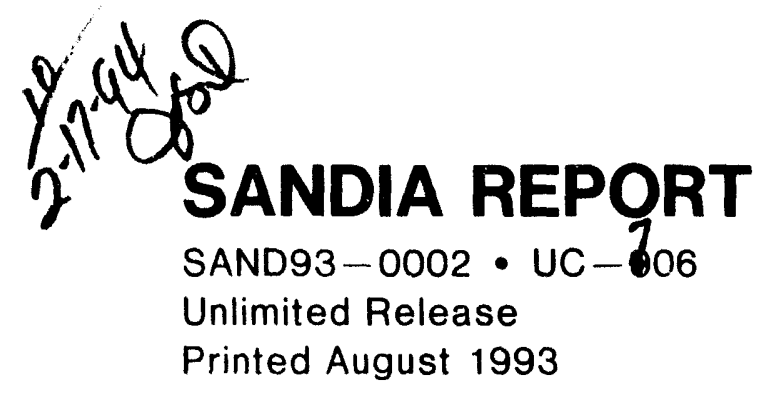

\title{
Intra-Building Telecommunications Cabling Standards for Sandia National Laboratories, New Mexico
}

\author{
R. L. Adams
}

\section{Prepared by}

Sandia National Laboratories

Albuquerque, New Mexico 87185 and Livermore, California 94550

for the United States Department of Energy

under Contract DE-AC04-76DP00789 
Issued by Sandia National Laboratories, operated for the United States Department of Energy by Sandia Corporation.

NOTICE: This report was prepared as an account of work sponsored by an agency of the United States Government. Neither the United States Government nor any agency thereof, nor any of their employees, nor any of their contractors, subcontractors, or their employees, makes any warranty, express or implied, or assumes any legal liability or responsibility for the accuracy, completeness, or usefulness of any information, apparatus, product, or process disclosed, or represents that its use would not infringe privately owned rights. Reference herein to any specific commercial product, process, or service by trade name, trademark, manufacturer, or otherwise, does not necessarily constitute or imply its endorsement, recommendation, or favoring by the United States Government, any agency thereof or any of their contractors or subcontractors. The vi:ws and opinions expressed herein do not necessarily state or reflect those of the United States Government, any agency thereof or any of their contractors.

Printed in the United States of America. This report has been reproduced directly from the best available copy.

Available to DOE and DOE contractors from

Office of Scientific and Technical Information

PO Box 62

Oak Ridge, 'TN 37831

Prices available from (615) 576-8401, FTS 626-8401

Available to the public from

National Technical Information Service

US Department of Commerce

5285 Port Royal Rd

Springfield, VA 22161

NTIS price codes

Printed copy: A03

Microfiche copy: $\mathrm{A} 01$ 


\title{
Intra-Building Telecommunications Cabling Standards for Sandia National Laboratories, New Mexico
}

\author{
R. L. Adams \\ Communications Department \\ Sandia National Laboratories \\ Albuquerque, NM 87185
}

\begin{abstract}
This document establishes a working standard for all telecommunications cable installations at Sandia National Laboratories, New Mexico. It is based on recent national commercial cabling standards. The topics addressed are Secure and Open/Restricted Access telecommunications environments and both twisted-pair and optical-fiber components of communications media.
\end{abstract}

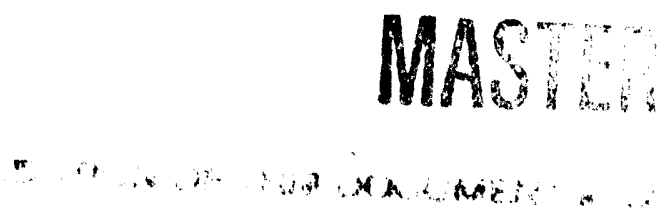




\section{Acknowledgment}

For his patience and advice, I would like to thank T. L. Bisbee, 9538, from whom I inherited the telecommunications cabling distribution responsibility. His previous efforts, documented in SAND90-0533, June 1990, were the catalyst for the creation of this docum ent. Special thanks also go to S. A. Gossage, 1954, whose endless enthusiasm, interest, and knowledge in the area of optical communications has so inspired me, and to all my fellow Sandians for their patience and assistance through years of trials and efforts to satisfy their communications needs. 


\section{Preface}

In the early $1980 \mathrm{~s}$, prompted by the need to distribute classified computing capabilities, the Communications Design and Services Departments initiated a Lab-wide Secure computer data distribution system. Several major buildings were chosen as concentration points for the communication equipment required for the distribution system. These concentration points, referred to as Technical Control Centers (TCCs), were selected to serve geographic areas within secured Tech Areas I, IV, and III/V. Originally, the Secure distribution system was composed of copper wiring systems, both intra- and inter-building. It now includes an optical-fiber backbone that interconnects the TCCs and all major buildings. The entire Secure distribution system conforms to the U.S. Department of Energy's Protected Distribution System security requirements.

In the recent past, technology and world relations have undergone enormous change that has created numerous challenges. The challenge faced by the Communications Department at Sandia is to provide two telecommunication distribution systems capable of supporting state-of-the-art communication technologies for all communication needs. One distribution system will be dedicated for Secure telecommunication needs and the other will be for Open/Restricted Access telecommunication needs. The only possible way to create two distinct distribution systems with identical capabilities is to implement one Cabling Standard.

This document defines the standard for transmission media and the termination hardware. A companion document, SAND93-0863, Intra-Building Telecommunications Cabling Pathways and Spaces Standards for Sandia National Laboratories, New Mexico, is forthcoming from Facilities Engineering, Department 7906. It will incorporate Secure installation requirements such as conduit, labeling, and physical markings and corresponding Open/ Restricted Access installation issues.

This Cabling Standard is based on recent national standards which have been modified, where appropriate, to meet Sandia's specific telecommunication needs. Implementation of the e standards during the recabling of all major buildings will guarantee Sandia's ability to remain one of the premiere high-technology development centers in the world. 


\section{Contents}

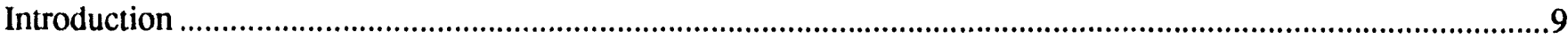

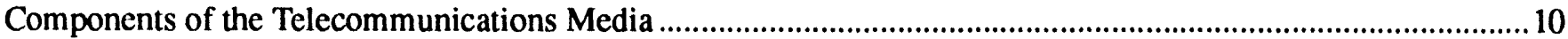

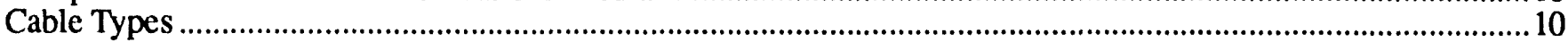

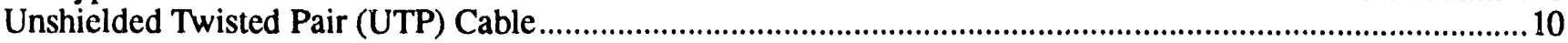

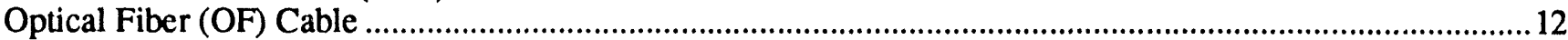

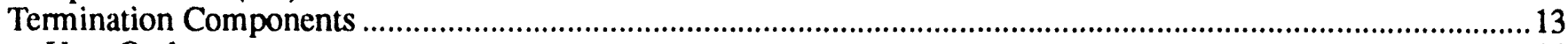

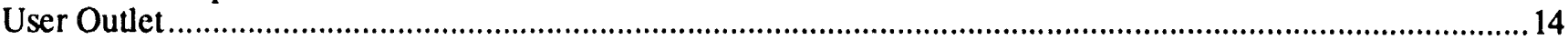

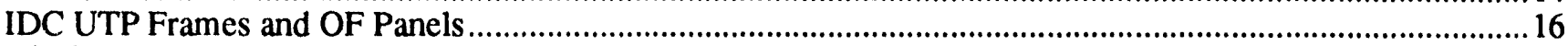

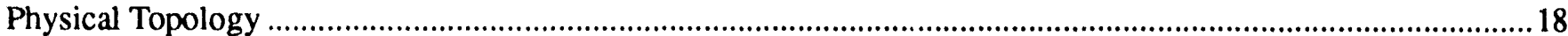

\section{Figures}

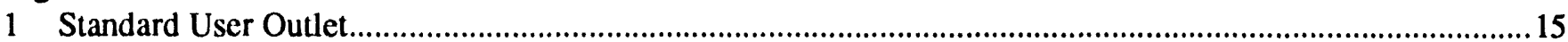

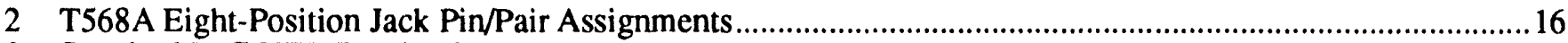

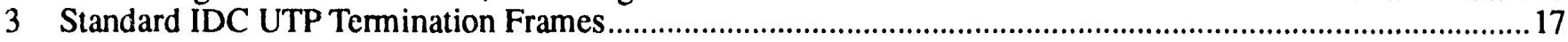

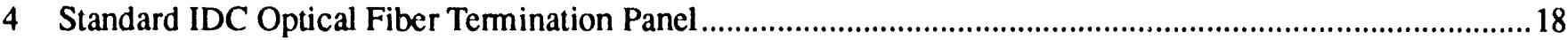

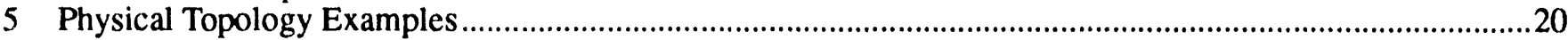

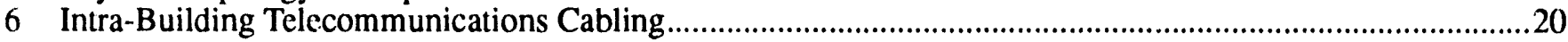

\section{Tables}

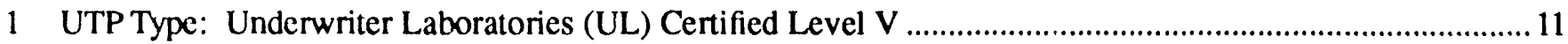

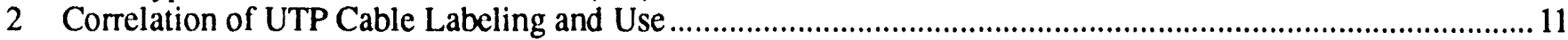

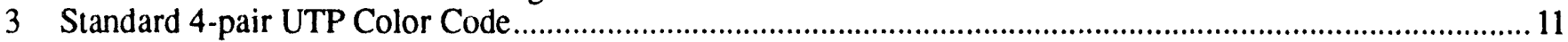

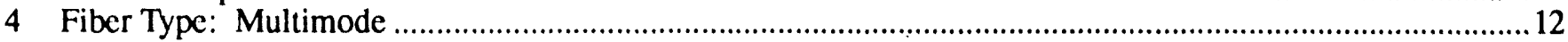

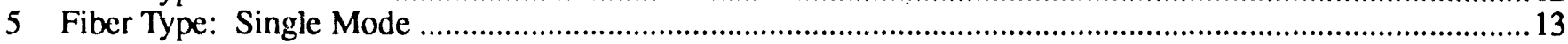

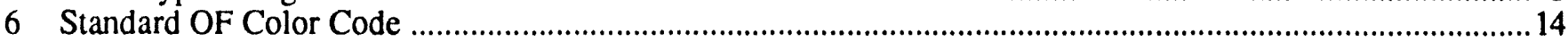

7 Standard Components Required for One User Outlet ................................................................................

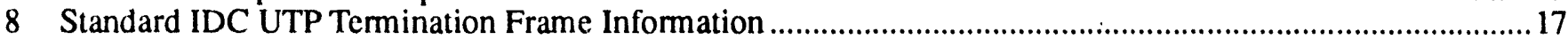

9 Standard IDC Optical Fiber Termination Panel Information ...........................................................................19 


\section{Acronyms}

ANSI

ATM

AT\&T

DOE

EIA

EMF

EUTP

FDDI

IDC

IEC

LAN

LIU

NEXT

OF

PDS

ST

TIA

TP-PMD

TSB

TCC

UL

UTP
American National Standards Institute

asynchronous transfer mode

American Telephone and Telegraph

Department of Energy

Electronic Industries Association

electromagnetic field

enhanced unshielded twisted pair

Fiber Distributed Data Interface

Intermediate Distribution Closet

International Electronic Committee

Local Area Network

Lightguide interconnection unit

near end crosstalk

optical fiber

Protected Distribution System

straight tip

Telecommunications Industry Association

twisted pair-physical media dependent

Technical Systems Bulletin

Technical Control Center

Underwriters Laboratories

unshielded twisted pair 


\section{Intra-Building Telecommunications Cabling Standards for Sandia National Laboratories, New Mexico}

\section{Introduction}

The advantage of implementing cabling standards in highly technical areas is that all areas of telecommunications will be positively affected with regard to cost, schedule, and performance. Recent national and international efforts to standardize communications protocols illuminated the need to standardize intra-building telecommunications cabling. In July 1991, the American National Standards Institute Electronic Industries Association/Telecommunications Industry Association (ANSI EIA/TIA) published Commercial Building Telecommunications Wiring Standard, EIAVTIA-568, to "define a generic telecommunications wiring system for commercial buildings that will support a multiproduct, multivendor environment." Before the publication of that document, telecommunications cabling had no transmission standards at all. Cabling choices were frequently predicated on specific vendor equipment requirements. The cables of choice ranged from twisted pair to coaxial to optical fiber, with literally hundreds of each type. In a facility such as Sandia's, every unique telecommunication cabling solution was typically a throwaway for two reasons. First, Sandia's "churn" rate (the relocation of staff) has risen as high as $30 \%$ per year in recent years. The chance of relocating staff to an area with cabling equivalent to that vacated was extremely small. Second, vendors (for the most part) were interested only in selling and installing products that satisfied immediate customer needs. Little, if any, consideration was given to future telecommunication needs for the life of the building. Replacement of these throwaway systems resulted in additional recabling costs, loss of time, and disruption of operations. This seemingly endless burden of replacing throwaway systems can be stopped only by implementing cabling standards.
The implementation of the cabling standards contained in this document will result in consistent state-of-the-art intra-building telecommunications cabling infrastructures in all areas. The standards in this document are based on current national standard documents such as those in the following list. Sandia's unique advanced telecommunication requirements have been accommodated by the proper modifications to these national standards in areas such as media types, quantities, and security requirements.

ANSI EIA/TIA publications:

Document 568, Commercial Building Standard for Telecommunications Wiring Standard

Document 569, Commercial Building Standard for Telecommunications Pathways and Spaces

Document 570, Residential and Light Commercial Telecommunications Wiring Standard

ANSI Technical Systems Bulletins:

TSB 36, Additional Cable Specifications for Unshielded Twisted Pair Cables

TSB 40, Additional Transmission Specifications for Unshielded Twisted Pair Connecting Hardware

Again, implementing the cabling standards contained in this document as part of remodeling, recabling, and cabling of new construction projects will result in consistent state-of-the-art intra-building telecommunications cabling infrastructures. Some of the state-of-the-art technologies that will be supported by the intrabuilding cable infrastructure are Circuit and Packet Switched Networks (PBX/5ESS Voice and Low-Speed Data), Local Area Networks (Ethernet, Token Ring, Fiber and Copper Dis- 
tributed Data Interface), and Wide Area Networks (Asynchronous Transfer Mode). These technologies can be delivered to every desk and can transport data at rates sufficient to support all existing applications (such as Voice, Text and Graphics, Still Images, Full-motion Video), as well as applications to be defined in the future.

\section{Components of the Telecommunications Media}

Components of the telecommunications media are critical to the overall transmission capabilities of any distribution system. For Sandia to continue as a premeire high-technology research and development center, all telecommunications infrastructure components must be of the highest quality. All components specified in this document meet (or exceed) the highest levels of performance as stated in national telecommunications standards, and some, such as single mode optical fibers, exceed current national standard cable types. Sandia's state-of-the-art technologies mandate the inclusion of such advanced telecommunications components in all intra-building cabling infrastructures.

This document establishes cabling standards for the two separate telecommunications systems required at Sandia. These systems, the Secure system and the Open/Restricted Access system, must have identical capabilities. The standards set forth in this document are for cable types and termination components to ensure these identical capabilities. They meet or exceed recent (1991) national standards and art expected to meet not only current telecommunications needs, but needs for communications-media technology yet to be developed.

\section{Cable Types}

The standard cable types for all intra-building telecommunications at Sandia are unshielded twisted pair (UTP) and optical fiber (OF). The standard intra-building cable distribution to each user outlet at Sandia includes three 4-pair UTP cables, one 4-fiber multimode cable, and one 4-fiber single mode cable.

\section{Unshielded Twisted-Pair Cable}

Manufacturing UTP cable capable of transmitting high data rates requires advanced construction techniques and superior materials. This highquality UTP cable currently supports data rates of $100 \mathrm{Mbps}$. This is the same data rate used by the optical interface in the Fiber Distributed Data Interface (FDDI) Local Area Network (LAN) standard. The ANSI X3T9.5 (FDDI) working group has officially identified the $100 \mathrm{Mbps}$ capability of UTP cable as the twisted pair-physical media dependent (TP-PMD) application. In the near future, asynchronous transfer mode (ATM) equipment vendors will be transmitting data rates of $155 \mathrm{Mbps}$ over this same high-quality UTP cable.

The standard intra-building cable distribution to each outlet at Sandia will include three 4-pair UTP cables. Each UTP cable must meet specifications contained in Table 1.

This type of 4-pair UTP cable is identified in ANSI EIA/TIA TSB 36 as Category 5 cable. Underwriters Laboratories has recently initiated a test and certification program for all 100-ohm twisted pair cables. UL labeling differs slightly from ANSI EIA/TIA TSB 36 labeling. UL-certified cables will be labeled Level I through Level V, corresponding to ANSI EIA/TIA TSB 36 labels of Category 1 through Category 5. In conversation, the same cable may be referred to as "Level V," "Category 5," "enhanced unshielded twisted-pair (EUTP)," or "low-loss extended-frequency" cable. Table 2 correlates EIA categories to UL levels and lists bit rates and common applications for each category or level.

Multipair (greater than 4-pair) UTP cables are not currently available with Level $\mathrm{V}$ performance capabilities. Level III is available now; Level IV has recently been designed by $A^{\prime} I \& T$ but is not currently in production. The basic difficulty in producing a multipair cable with extended frequency capabilities is physical assembly, i.e., creating unique twist ratios for each pair in the cable and twist ratios for bundles of pairs. The physical positioning of electrical conductors in near proximity causes many electrical phenomena, two of which are near end crosstalk (NEXT) coupling loss and inductance. Such electrical properties must be addressed by cable construction.

All 4-pair UTP cables have standard color code, which is shown in Table 3. 


\section{Table 1. UTP Type: Underwriter Laboratorles (UL) Certfled Level V}

Conductor Quantity

Conductor Gauge Size

Conductor Impedance

Conductor Pair Attenuation
Four twisted pairs

24 AWG

$100 \mathrm{ohms}( \pm 15 \%)$ from 1 to $100 \mathrm{MHz}$

$\leq 6.3 \mathrm{~dB}$ per $1000 \mathrm{ft}$

(a) $20^{\circ} \mathrm{C}$ for $1 \mathrm{MHz}$

$\leq 20 \mathrm{~dB}$ per $1000 \mathrm{ft}$

(a) $20^{\circ} \mathrm{C}$ for $10 \mathrm{MHz}$

$\leq 67 \mathrm{~dB}$ per $1000 \mathrm{ft}$

(a) $20^{\circ} \mathrm{C}$ for $100 \mathrm{MHz}$

Worst Pair Near End Crosstalk (NEXT) $\geq 62 \mathrm{~dB} @ 1000 \mathrm{ft}$ for $1 \mathrm{MHz}$

$\geq 47 \mathrm{~dB}$ @ $1000 \mathrm{ft}$ for $10 \mathrm{MHz}$

$\geq 32 \mathrm{~dB} @ 1000 \mathrm{ft}$ for $100 \mathrm{MHz}$

0.19 in. (Riser), 0.2 in. (Plenum)

$18.4 \mathrm{lb} / 1000 \mathrm{ft}$ (Riser), $19.9 \mathrm{lb} / 1000 \mathrm{ft}$ (Plenum)

Cable Weight

\section{Table 2. Correlation of UTP Cable Labeling and Use}

\begin{tabular}{|c|c|c|c|}
\hline $\begin{array}{c}\text { ANSI } \\
\text { EIA/TIA TSB } 36 \\
\text { Category }\end{array}$ & $\begin{array}{c}\text { Underwriter } \\
\text { Laboratories } \\
\text { Level }\end{array}$ & Bit-Rate & Common Network Applications \\
\hline $1 \& 2$ & I \& II & & $\begin{array}{l}\text { Typically used for voice and low-speed data } \\
\text { in the Kbps range }\end{array}$ \\
\hline 3 & III & $\leq 10 \mathrm{Mbps}$ & $\begin{array}{l}\text { 4Mbps IBM Token Ring and 10Mbps } \\
\text { Ethemet }\end{array}$ \\
\hline 4 & IV & $\leq 16 \mathrm{Mbps}$ & 16Mbps IBM Token Ring \\
\hline 5 & $\mathrm{~V}$ & $\leq 100 \mathrm{Mbps}$ & 100Mbps TP-PMD Token Ring \\
\hline
\end{tabular}

Table 3. Standard 4-Pair UTP

Color Code

\begin{tabular}{cl} 
Pair Number & \multicolumn{1}{c}{ Pair Colors } \\
\hline 1 & White/Blue \\
2 & White/Orange \\
3 & White/Green \\
4 & White/Brown \\
\hline \hline
\end{tabular}




\section{Optical Fiber (OF) Cable}

Optical fibers have many advantayes over metallic conductors. Optical fibers are largely immune to external electromagnetic fields (EMF) and internal conductor signal coupling, are capable of withstanding atmospheres that are caustic to metallic conductors, and are capable of very high bit-rate transmissions across very long distances.

The standard intra-building cable distribution to each outlet at Sandia will include one 4-fiber multimode cable and one 4-fiber single mode cable.

These high-quality cables have been adopted by national standards committees such as EIA, IEEE 802, FDDI, and IEC. Sandia's standard optical fiber cables, both multimode and single mode, are currently AT\&T products. Until another vendor's product is qualified by Sandia, both Multimode and Single Mode OF cables must be obtained from AT\&T. The critical factor that forces sole-make selection is compatibility. Compatibility must be maintained with the existir g Sandia inter-building
OF distribution system. The inter-building distribution system represents over 10 years of design and installation effort and contains more than $7,000,000$ installed fiber feet. The total dollar investment is in the tens of millions. Other manufacturers' optical fibers have been tested at Sandia for interoperability with AT\&T optical fibers. The testing revealed dimensional inconsistencies such as core diameter, eccentricity, and concentricity, which induce unpredictable coupling loss between dissimilar fibers. The tests also revealed critical transmission compatibility problems, such as intolerable reflectivity at the point of contact between dissimilar fibers. In summary, the use of dissimilar fibers causes unpredictable optical transmission characteristics and prohibits the realization of maximum transmission capabilities built into each component throughout the entire optical distribution system at Sandia.

The multimode and single mode cables must meet the specifications contained in Table 4 and Table 5.

Table 4. Fiber Type: Multimode

\begin{tabular}{ll} 
Manufacturer & AT\&T \\
Fiber Quantity & Four fibers \\
Fiber Size & 62.5 -micron core diameter \\
& 125 -micron cladding diameter \\
Numerical Aperture & 0.275 \\
Fiber Attenuation & $\leq 3.4 \mathrm{~dB} / \mathrm{km} @ 850 \mathrm{~nm}$ \\
& $\leq 1.0 \mathrm{~dB} / \mathrm{km} @ 1300 \mathrm{~nm}$ \\
Fiber Bandwidth & $\geq 150 \mathrm{MHz}-\mathrm{km} @ 850 \mathrm{~nm}$ \\
& $\geq 500 \mathrm{MHz}-\mathrm{km} @ 1300 \mathrm{~nm}$ \\
Cable Outside Diameter & $0.175 \mathrm{in}$. for Riser-rated cable \\
& $0.195 \mathrm{in}$ for Plenum-rated cable \\
& $1.2 \mathrm{lb} / 100 \mathrm{ft}$ for Riser-rated cable \\
Cable Weight & $1.4 \mathrm{lb} / 100$ ft for Plenum-rated cable \\
& LGBC-004A-LRX (Riser) \\
Product Code & LGBC-004A-LPX (Plenum) \\
& 104272414 (Riser) \\
AT\&T COMCODE & 104272497 (Plenum) \\
\hline
\end{tabular}


Table 5. Fiber Type: Single Mode

$\begin{array}{ll}\text { Manufacturer } & \text { AT\&T } \\ \text { Fiber Quantity } & \text { Four fibers } \\ \text { Fiber Size } & 8.3 \text {-micron core diameter } \\ & 125 \text {-micron cladding diameter } \\ \text { Mode Field Diameter } & 8.8 \pm 0.5 \text { microns } \\ \text { Zero Dispersion Wavelength } & 1310 \pm 10 \mathrm{~nm} \\ \text { Fiber Attenuation } & \leq 0.4 \mathrm{~dB} / \mathrm{km} @ 1310 \mathrm{~nm} \\ & \leq 0.3 \mathrm{~dB} / \mathrm{km} @ 1550 \mathrm{~nm} \\ \text { Fiber Dispersion } & \leq 2.8 \mathrm{ps} / \mathrm{nm} \text {-km @ } 1310 \mathrm{~nm} \\ & \leq 18 \mathrm{ps} / \mathrm{nm}-\mathrm{km} @ 1550 \mathrm{~nm} \\ \text { Cable Outsice Diameter } & 0.175 \mathrm{in} . \text { for Riser-rated cable } \\ & 0.195 \mathrm{in} . \text { for Plenum-rated cable } \\ \text { Cable Weight } & 1.2 \mathrm{lb} / 100 \mathrm{ft} \text { for Riser-rated cable } \\ & 1.4 \mathrm{lb} / 100 \mathrm{ft} \text { for Plenum-rated cable } \\ \text { Product Code } & \text { LGBC-004A-SRX (Riser) } \\ & \text { LGBC-004A-SPX (Plenum) } \\ \text { AT\&T COMCODE } & 104272455 \text { (Riser) } \\ \end{array}$

NOTE: The decision whether to use cables having Riser- or Plenum-rated jacket material (for both UTP and OF cables) will depend on the particular installation. Sandia's cable jacket of choice is Plenum. However, since all Secure (Red) distribution systems require conduit as the pathway conveyance, cables having Riserrated jacket material may be used. Other pathway conveyances, such as ladders or trays, may be installed for Open/Restricted Access (Black) distribution systems. These pathway conveyances mandate the installation of cables having Plenum-rated jacket materials.

All OF cables, both multimode and single mode, have a standard color code, shown in Table 6.

\section{Termination Components}

Cable termination occurs at the user location and in an intermediate distribution closet
(IDC). At the user location, a single wallmounted outlet will terminate both UTP and OF cables. This type of outlet is commonly referred to as a multimedia outlet. Buildings inside the Secure Tech Area will have two distribution systems (Red and Black) installed. Each occupant in these buildings will have one Red outlet and one Black outlet. If a building is located outside the Secure Tech Area, it will have only an Open/Restricted Access (Black) distribution system installed. Each occupant in these buildings will have a Black outlet. In the IDC, user UTP cables will terminate on wallmounted UTP frames and user OF cables will terminate in wall-mounted OF distribution panels. Red/Black cable and equipment separation (per DOE PDS requirements) will be accomplished both at the user outlet and in the IDC. 
Table 6. Standard OF Color Code

\begin{tabular}{cc}
$\begin{array}{c}\text { Fiber } \\
\text { Number }\end{array}$ & $\begin{array}{c}\text { Fiber Coating } \\
\text { Color }\end{array}$ \\
\hline 1 & Blue \\
2 & Orange \\
3 & Green \\
4 & Brown \\
\hline \hline
\end{tabular}

\section{User Outlet}

At Sandia, a single user outlet must accommodate all of the required cables and conductors. The standard intra-building cable distribution to each user outlet includes three 4-pair UTP cables, one 4-fiber multimode cable and one 4-fiber single mode cable. Currently, only one manufacturer (Panduit) is producing an outlet that will accommodate this cable/conductor configuration. The Panduit outlet is made of high-impact thermoplastic material with an Underwriters Laboratories flammability rating of U.L. $94 \mathrm{~V}$.O. It can accommodate up to eight termination modules. Termination module types (UTP and/or OF) will be arranged as in Figure 1. As shown in the figure, the baseplate has a built-in optical fiber cable spool designed to properly store cable slack.

UTP termination/connecting components inside these outlets must match the transmission capabilities of the UTP conductors. The standard UTP termination/connecting components must be UL-certified to ANSI EIA/TIA TSB 40 Category 5. This standard will ensure high bit-rate $(100 \mathrm{Mbps}$ or more, end-to-end functionality via UTP.

The recent ANSI EIA/TIA TSB 40 standard categorizes UTP termination/connecting components by transmission capabilities. These termination/ connecting component categories correspond directly to the ANSI EIATIA TSB 36 UTP cable categories. Underwriter Laboratories has recently established a test and certification process to independently certify these new termination/ connecting components. Products found to be in compliance with a particular performance program
(ANSI EIA/TIA TSB 40) may be marked with the following statement either on the product or on the smallest-unit carton in which the product is packaged.

\section{ALSO EVALUATED BY UNDERWRITERS LABORATORIES INC. IN ACCORDANCE WITH ANSI EIATTIA TSB 40 CATEGORY 5}

Optical Fiber termination/connecting components inside the user outlet must match the transmission capabilities of the OF conductors. The standard optical connector/coupler for multimode and single mode fibers at Sandia is currently the AT\&T straight tip (ST).

This high-quality connector/coupler type has been adopted by many national standards committees. The Sandia standard, being sole-make AT\&T, is based on three factors. First, AT\&T, the creator of the ST technology, has not licensed manufacturing rights to any other optical component manufacturer. All other "ST compatible" components are reverse-engineered, yielding a multitude of inferior or unknown performance characteristics. Second, Sandia testing of other manufacturer's components for interoperability with AT\&T components revealed dimensional inconsistencies that induced unpredictable connector coupling loss, and material deficiencies that resulted in component breakage or low coupling repeatability. Third, compatibility must exist with the entire Sandia inter-building OF distribution system. This inter-building distribution system represents over 10 years of design and installation effort, more than 7,000,000 fiber feet, and thousands of AT\&T ST connectors and couplers. The total dollar investment is in the tens of millions. As with the OF cable, until another vendor product is qualified by Sandia, both multimode and single mode optical fiber connectors and couplers will be sole-make AT\&T STs.

The list in Table 7 contains Panduit and AT\&T component part numbers and quantities required to assemble one standard user outlet at Sandia. 


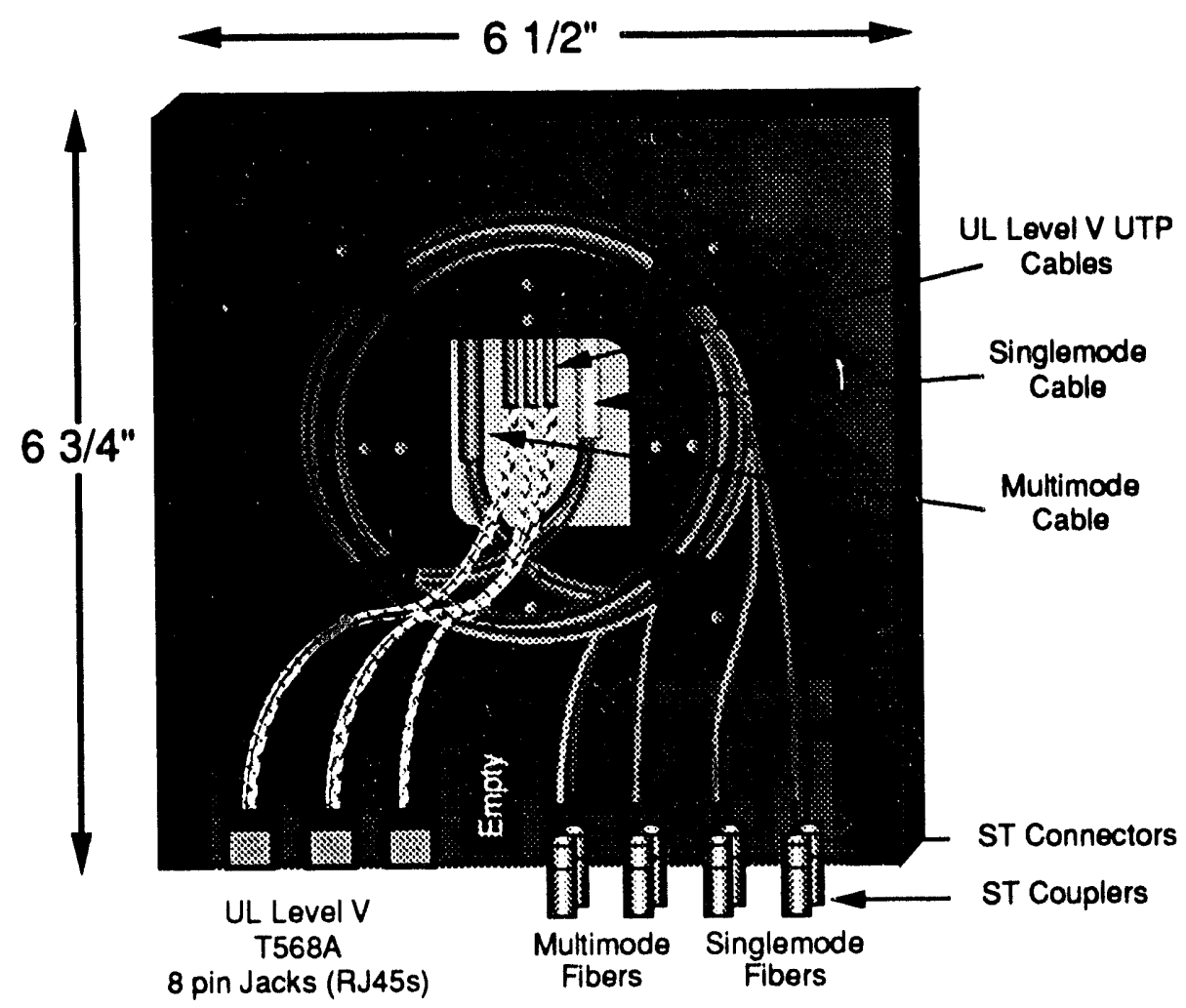

Figure 1. Standard User Outlet

Table 7. Standard Components Required for One User Outlet

\begin{tabular}{|c|c|c|c|c|}
\hline Description & Manufacturer & $\begin{array}{l}\text { Part Number/ } \\
\text { COMCODE }\end{array}$ & Color & Quantity \\
\hline Baseplate and Faceplate & Panduit & $\begin{array}{l}\text { MBXD8RD or } \\
\text { MBXD8BL }\end{array}$ & $\begin{array}{c}\text { Red } \\
\text { Black }\end{array}$ & 1 \\
\hline Level V UTP 568A* module & Panduit & MUJC588AWH & White & 3 \\
\hline Dual ST coupler panel & Panduit & MM38DWH-X & White & 4 \\
\hline Blank panel & Panduit & MMB 1WH-X & White & 1 \\
\hline Multimode STII connector & AT\&T & 106812274 & N/A & 4 \\
\hline Multimode STII coupler & AT\&T & 104148028 & N/A & 4 \\
\hline Single Mode STII connector & AT\&T & 106812258 & N/A & 4 \\
\hline Single Mode STII coupler & AT\&T & 105271142 & N/A & 4 \\
\hline
\end{tabular}

*568A is a specific conductor configuration. (Sce Figure 2.) 


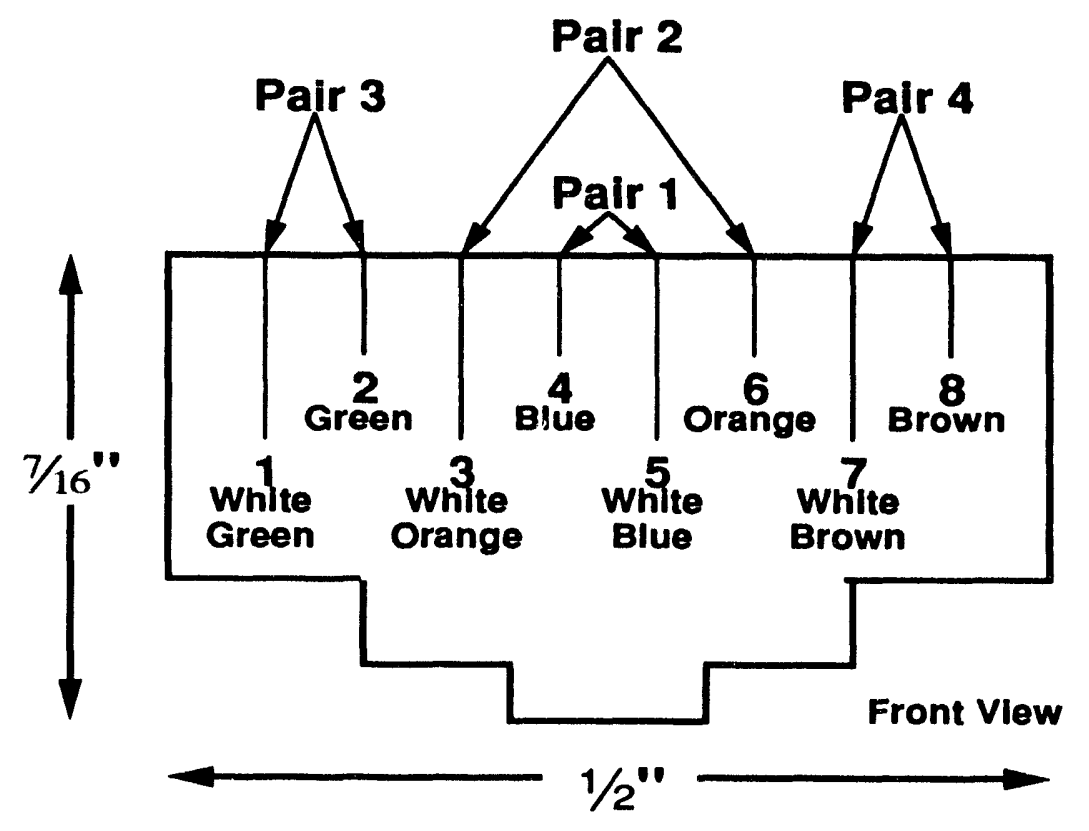

Figure 2. T568 Eight-Position Jack Pin/Pair Assignments

\section{IDC UTP Frames and OF Panels}

The IDC UTP frames and OF panels must accommodate the number of cables and conductors required by this standard. Again, the standard telecommunications cable configuration for a user outlet at Sandia is three 4-pair UTP cables, one 4fiber multimode cable, and one 4-fiber single mode cable. Each IDC is capable of servicing hundreds of users. Therefore, the resultant number of conductors terminating in an IDC is high and requires extreme attention to space allocation for termination.

Termination Frame. The UTP termination/connecting components inside the IDC must match the transmission capabilities of the UTP conductors. The standard UTP termination/connecting components at Sandia must be UL-certified to EIA/TIA TSB 40 Category 5. Again, this standard will ensure high bit-rate (100Mbps or more) end-to-end functionality via UTP.

Currently, AT\&T is the only manufacturer producing a termination/connecting frame with UL-certified EIA/TIA TSB 40 Level V components that can accommodate Sandia's cable/conductor configuration and space limitation requirements. The AT\&T 110 Patch Panel System has been ULcertified Level $\mathrm{V}$ and allows extremely dense termination of UTP conductors. The AT\&T 110 Patch Panel System also provides consistent, reliable, repeatable, gas-tight connections for data, voice, and other low-voltage circuits. Maintenance concerns such as frequent patching for adds, deletes, and modifications, as well as ruggedness and ease of termination, were addressed in AT\&T's component designs. (See Figure 3.)

Table 8 part numbers include all components required to terminate up to 3600 Red unshielded twisted pairs and up to 3000 Black unshielded twisted pairs in an IDC.

Termination Panel. The OF termination/ connecting components inside the IDC must match the transmission capabilities of the OF conductors. The standard optical connector/ coupler for both multimode and single mode fibers at Sandia is the AT\&T ST. 


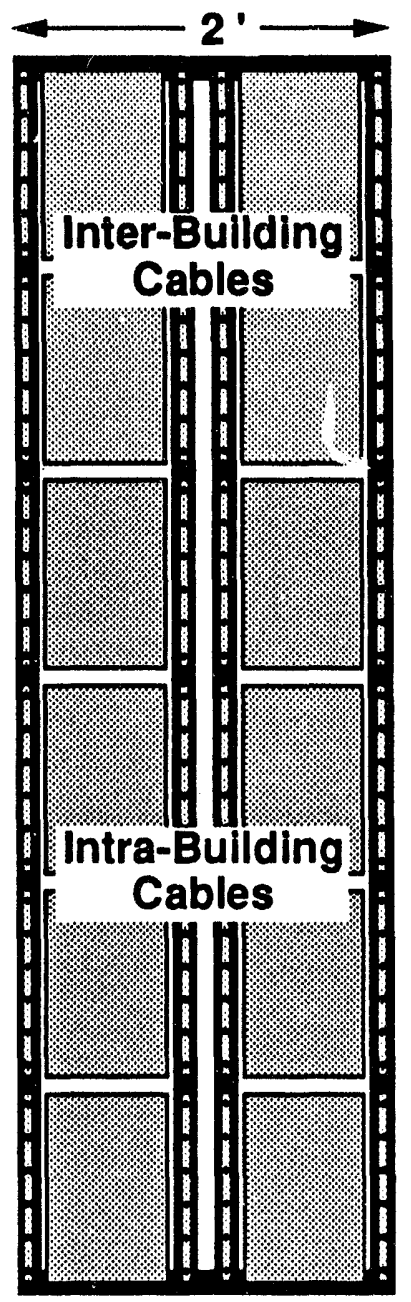

Red UTP

Termination Frame

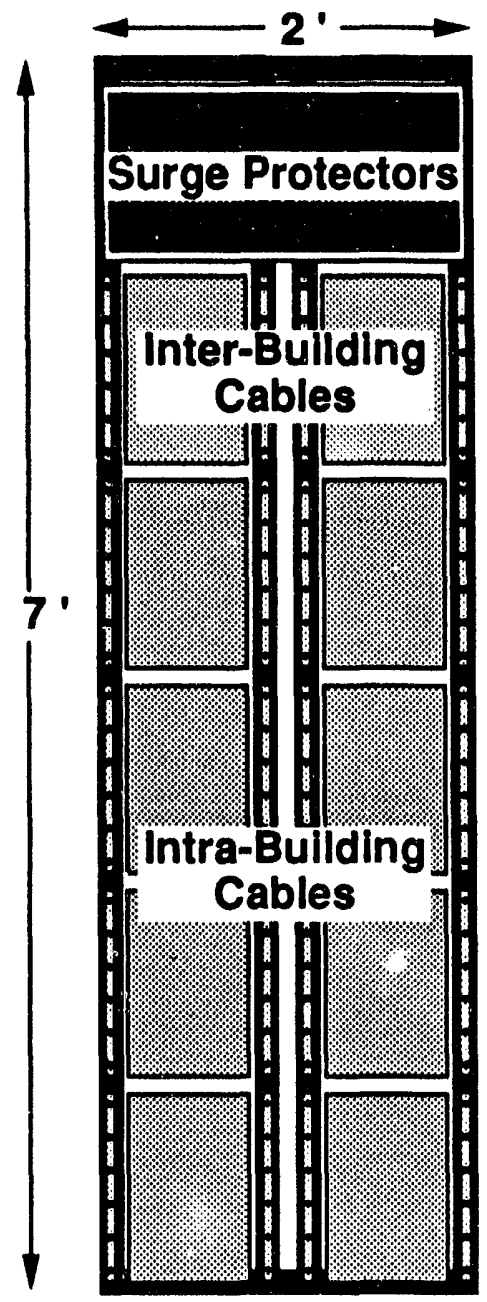

Black UTP

\section{Termination Frame}

Figure 3. Standard IDC UTP

Termination Frames

\section{Table 8. Standard IDC UTP Termination Frame Information}

\begin{tabular}{lcccc}
\multicolumn{1}{c}{ Description } & Manufacturer & COMCODE & Colors & Quantity \\
\hline $\begin{array}{l}\text { XLBET single-sided frame pre-assembled with } \\
\text { twelve 300-pair 110 punch-down block modules } \\
\text { and cable routing hardware }\end{array}$ & AT\&T & 105158182 & $\begin{array}{c}\text { Black or } \\
\text { Red }\end{array}$ & 1 \\
$\begin{array}{l}\text { XLBET single-sided frame pre-assembled with ten } \\
\text { 300-pair 110 punch-down block modules, 300 } \\
\text { surge protector jacks, and cable routing hardware }\end{array}$ & AT\&T & 106993017 & Black & 1 \\
\hline \hline
\end{tabular}


Currently, only one manufacturer (AT\&T) is producing a termination/connecting panel that will accommodate Sandia's cable/conductor configuration and space limitation requirements. The AT\&T lightguide interconnection unit (LIU) panel allows extremely dense termination of OF cables. Maintenance concerns such as frequent patching for adds, deletes, and modifications were designed into the products. (See Figure 4)

Table 9 part numbers include all OF panel components needed to terminate 24 optical fibers in an IDC.

\section{Physical Topology}

There are several physical topologies for intrabuilding telecommunications cabling: point-to-point, bus, ring, and star. The standard Sandia intra-building physical cabling distribution topology is star. This is also consistent with the ANSI EIA/TIA 568 document. (See Figure 5)

Because of its centralized hub, physical star topology provides maximum flexibility for configuration modifications and minimum administration. Network security can be accomplished by controlling access to the physical star hub, where LAN and other network hubs are located. Telecommunications technology advances can easily be accommodated by replacing out-dated hub equipment at the physical star hub. Network growth can be graceful and non-disruptive with modular hub electronics.

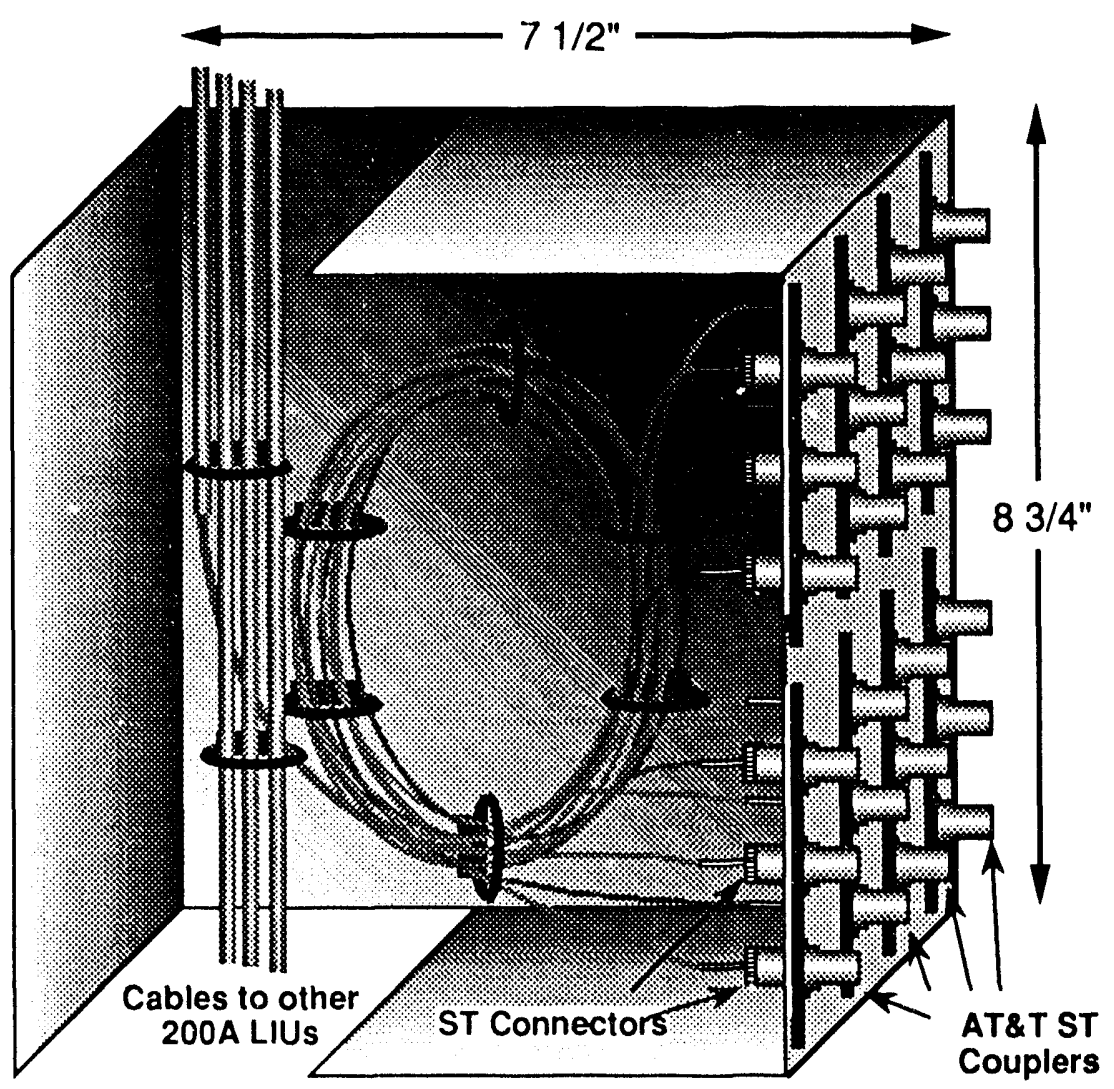

Figure 4. Standard IDC Optical Fiber Termination Panel 
Table 9. Standard IDC Optical Fiber Termination Panel Information

\begin{tabular}{lcccc}
\multicolumn{1}{c}{ Description } & Manufacturer & COMCODE & Colors & Quantity \\
\hline 200A LIU Enclosure & AT\&T & 105535926 & White & 1 \\
10A Coupling Panel & AT\&T & 104141858 & White & 4 \\
2A6 Vertical Trough & AT\&T & 106295520 & White & 1 \\
2A8 Horizontal Trough & AT\&T & 106479761 & White & 1 per 6 LIUs \\
Multimode STII Connector & AT\&T & 106812274 & N/A & 24 \\
Multimode STII Coupler & AT\&T & 104148028 & N/A & 24 \\
Single Mode STII Connector & AT\&T & 106812258 & N/A & 24 \\
Single Mode STII Coupler & AT\&T & 105271142 & N/A & 24 \\
\hline \hline
\end{tabular}

Physical star tupology can support all logical topologies. (Physical topology refers to the physical arrangement of cables. Logical topology refers to the method by which different nodes in a network communicate with one another. It involves protocols, access, and contention at the electronic circuit level.) Some popular networks and their required logical topologies are private branch exchange (PBX) requiring a logical star; Ethernet IEEE 802.3 carrier sense, multiple access/collision detect (CSMA/CD) requiring a logical bus; Token Bus token passing IEEE 802.4 requiring a logical bus, and Token Ring token passing IEEE 802.5 IBM $4 / 16 \mathrm{Mbps}$ and FDDI $100 \mathrm{Mbps}$ requiring a logical ring. All of these networks are easily implemented on physical star cabling.

Distance limitations for UTP cabling are derived from the ANSI EIATTIA 568 document, which states, "The maximum horizontal dis- tance (between user outlet and IDC) shall be 90 meters ... " Incorporating this distance limitation into an intra-building distribution system results in numerous challenges in building construction. IDC size, quantity, and placement are critical design considerations that affect overall cost and schedule. Pathways (conduits, cable trays, etc.) and spaces (IDCs) are an integral part of any intra-building telecommunications distribution system. A companion document, to this standard, SAND93-0863, Intra-Building Telecommunications Cabling Pathways and Spaces Standards for Sandia National Laboratories, New Mexico, will be created by Sandia Facilities Department 7906 to address all issues pertinent to Sandia's buildings.

The block diagram in Figure 6 is included as a graphical representation of the overall intrabuilding telecommunications cabling infrastructure. 

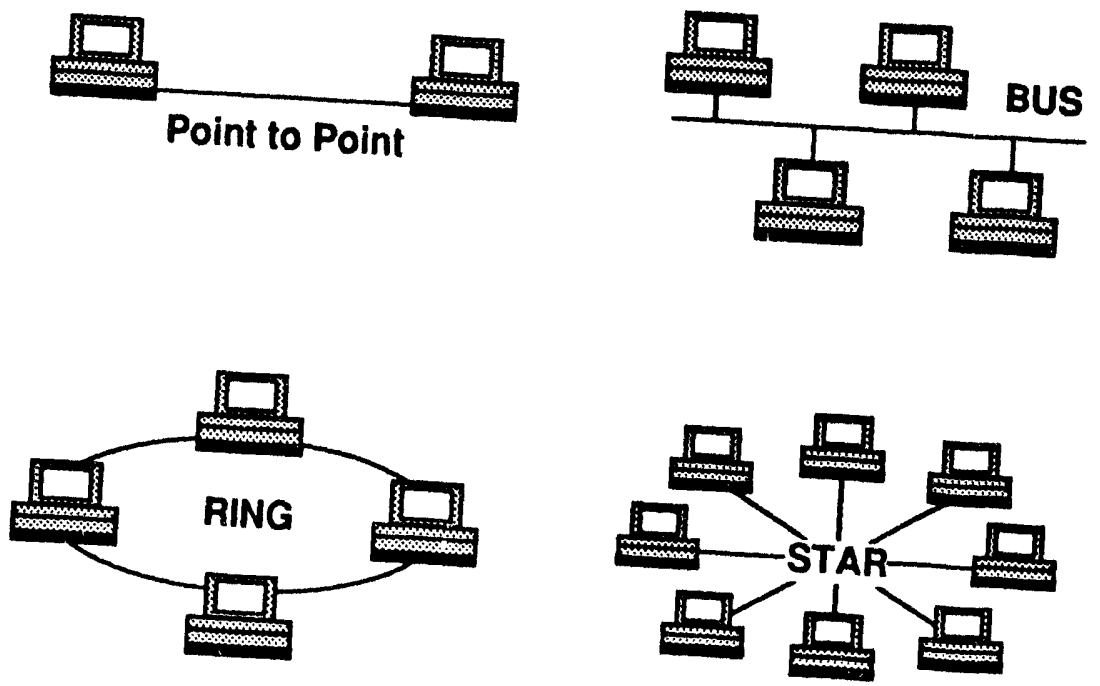

Figure 5. Physical Topology Examples

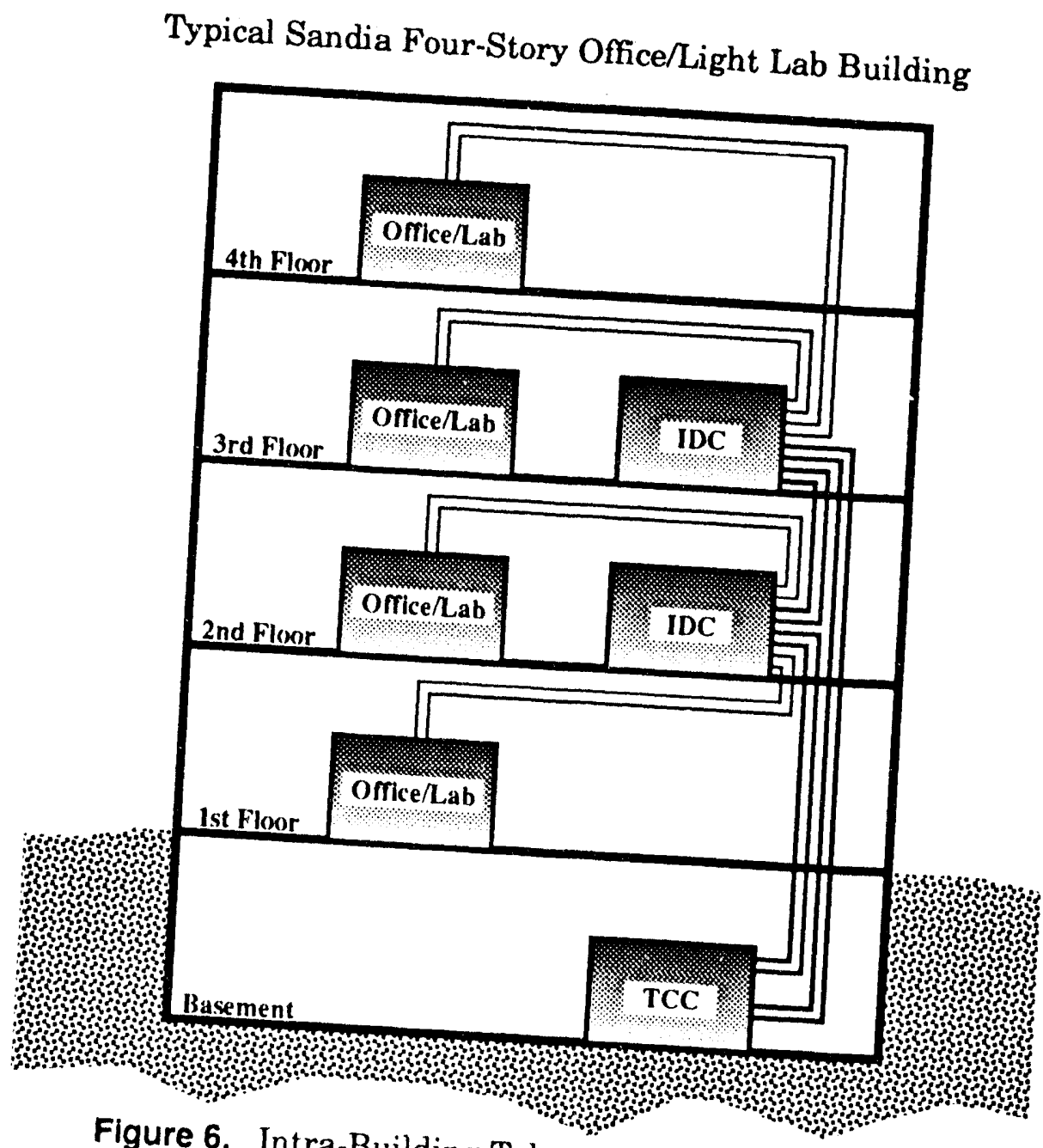

Figure 6. Intra-Building Telecommunications Cabling 
DISTRIBUTION:

$\begin{array}{rll}183 & 1955 & \text { R. L. Adams } \\ 1 & \mathbf{8 5 2 3 - 2} & \text { Central Technical Library } \\ 5 & 7141 & \text { Technical Library } \\ 1 & 7151 & \text { Technical Publications } \\ 10 & 7613-2 & \text { Document Processing } \\ & & \text { for DOE/OSTI }\end{array}$



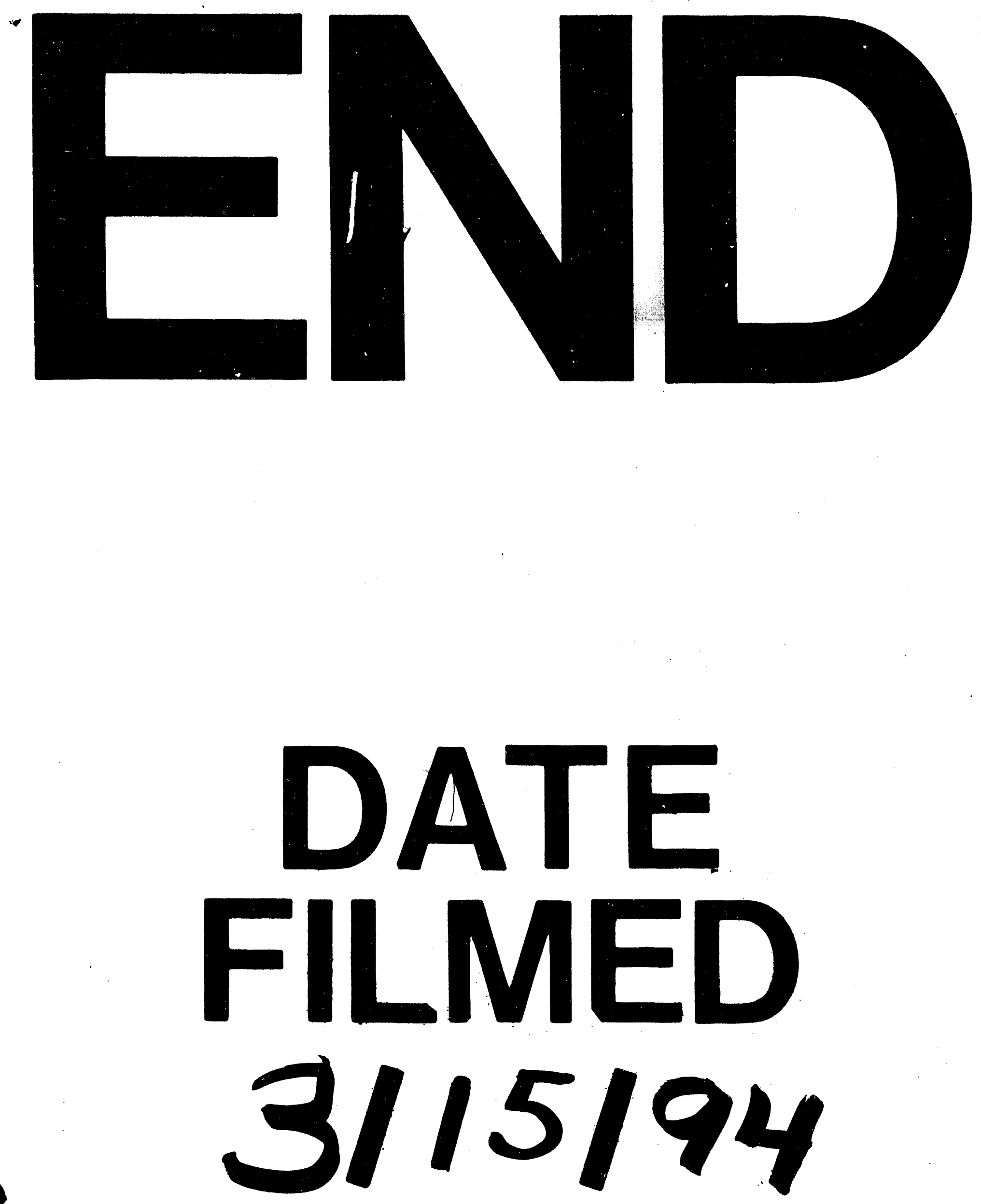

1 
